\title{
Facility Maintenance Management and Its Effects on Employee Performance: A Positivist Approach
}

\author{
Sipumelele Ntshebe ${ }^{1}$, Miston Mapuranga ${ }^{1}$, Thobekani $\operatorname{Lose}^{1} \&$ Yusuf Lukman ${ }^{1}$ \\ ${ }^{1}$ Centre of Entrepreneurship Rapid Incubator, Walter Sisulu University, South Africa \\ Correspondence: Sipumelele Ntshebe, Centre of Entrepreneurship Rapid Incubator, Walter Sisulu University, South \\ Africa.
}

Received: October 20, 2021

Accepted: January 19, 2022

Online Published: January 30, 2022

doi:10.5430/ijhe.v11n7p47

URL: https://doi.org/10.5430/ijhe.v11n7p47

\begin{abstract}
This study aims to investigate the role facility maintenance management plays on employee performance at a institution of higher learning in the Eastern Cape of South Africa. This study employed a quantitative research approach, and the data were gathered from 150 employees who were chosen through a random sampling method. The data were analyzed using the Statistical Package for the Social Scientist (SPSS) Version 24.0. The analysis was of frequencies and standard deviations. The study findings revealed that the current facilities at the institution need an upgrade to a level that is conducive, suitable, and adequate for employees to perform their duties satisfactorily to reach the objectives of the institution. An efficient method for preparing, scheduling, and coordinating facility maintenance tasks needs to be applied to ensure effective maintenance service is performed effectively. This empirical study provided fruitful implications for academicians by making a significant contribution to the facility maintenance literature by systematically exploring the effect of facility maintenance management on the employee performance at a higher learning institution within the Eastern Cape province of South Africa. This study, consequently, stands to greatly add new knowledge to the existing literature related to maintenance performance measurement in Africa, a research setting that has been neglected by academic researchers of late.
\end{abstract}

Keywords: facility maintenance management, institutions of higher learning, human resource

\section{Introduction}

Facility maintenance management (FMM) forms an integral part of the key strategic objectives to improve organizational performance in institutions. Achieving excellence in higher education is attached to many aspects, such as availability of facilities and their provisions supported by operative management Fadahunsi et al. (2019) noted that, globally, there is a link between the quality of higher education institutional facilities available and the quality of the outcome produced by the institution. According to Nik-Mat et al. (2011), in the last decade in Africa, the development of FMM has been sluggish, and the sector is still in its infancy. They further stated that the definition of FMM is poorly understood institution management and was not achieved in an efficacious manner (Nik-Mat et al., 2011). Facilities form part of a significant proportion of South African national assets. Facilities require maintenance to provide quality and favourable working conditions for the core business of institutions of higher learning (IHLIHLs). They are responsible for providing essential support to HR for the accomplishment of the institutional objectives (Dada et al., 2018). FMM has been elucidated by Oladokun and Ajayi (2018) as the aspect that incorporates various disciplines to ensure the institution functions by integrating employees, places, processes, and information technology. The efficiency and availability of quality facilities to supplement the performance of educators in the main function of teaching, learning, and research play an important role in influencing the rate of satisfaction and output in an institution (Ogbeifun, 2016).

As a point of departure, facilities, therefore, play an important and crucial role in enabling resource of the university; in fact, almost the entire learning process of the university is advanced by facilities such as lecture halls and offices. This study examined the role of FMM and its effect on employee performance at an IHL in the Eastern Cape (EC) of South Africa. The institution was established in terms of the Higher Education Act No. 101 of 1997, as amended. During the institutional growth process, the institution has considered developments, partnerships, mergers, and achievements. This approach has transformed the institution, allowing it to operate as a multi-campus organization where most of its students come from rural backgrounds. 


\subsection{Problem Statement}

Over the last decade, the institution in the EC has experienced a gradual increase in the number of students and academic activities, which led administrators to focus on new projects and procuring new facilities to counter the growing student body and to improve the quality of learning. Meanwhile, the currently existing facilities suffered insufficient maintenance, often making it difficult for employees to complete their tasks, which, in turn, affected the core institutional objectives of researching, teaching, and learning.

Dilapidated and neglected facilities create an environment that suppresses the performance of employees (Okafor \& Aigbavboa, 2019). The lack of maintenance on the institution has had a tremendous effect. Maintenance is performed in an ad hoc manner - only when there is a problem would an inspection of the facilities be conducted, suggesting that top management did not give much consideration to facility maintenance. The rate at which the IHL lost accreditation due to poor infrastructure necessitated a review of its FMM and its effect on employee performance.

The institution's vision for 2020 is to be a leading African comprehensive university focusing on innovative educational research community partnership programs. Currently, according to the Council of Higher Education 2018 report following an institutional audit, the institution has poor facilities. As student enrolment continues to increase, the institution is experiencing heavier use of existing facilities and an increased rate of decaying buildings. Poorly maintained facilities not only make it tough for students to learn effectively, but they also make it harder for employees to perform daily duties and to attract the best researchers and lecturers for the institution (Dada et al., 2018). Based on Ofide et al.'s (2015) commentary, facilities cannot remain new the whole duration of their existence; maintenance problems start to occur immediately after they are completed or installed, and therefore, maintenance is required to be carried out on those facilities to perform intended functions. Because there is a dearth of studies that have focused on the role of FMM on employee performance in IHLs in the EC province in South Africa, it is imperative that more research be done, if only to avert the high failure rate of IHLs in South Africa.

Therefore, this research paper is organized as follows: aim of the study, the objectives of the study, literature review, research methodology results, discussion and interpretation of findings, and conclusion.

\subsection{Aim of the Study}

The aim of the study was to examine the role of FMM and its effect on the performance of the employees at an IHL in the EC. The research also aimed to identify the problems that hinder maintenance process.

\subsection{Objectives of the Study}

- To examine the impact of FMM on the performance of the employees at an IHL

- To evaluate whether the current facilities create a suitable, conducive, and adequate working environment

The importance of the study was to highlight the failure of and problems related to facility maintenance of the institution and to highlight the overall effect it has on the performance of the employees of the institution. The study benefits the institution's stakeholders, which are the government, academic and support staff, the community, students, and donors, by supporting the establishment of good quality maintenance within the IHLs. The world is bombarded by various complexities such as global competitiveness and faced with the increasing importance of higher education to facilitate that competitiveness and economic development (Waller et al., 2019). Therefore, it is of the utmost importance for the institution in the EC to be competitive among other higher learning institutions. By identifying barriers that are not efficient and that are hindering maintenance improvement and by examining the role and effects of FMM on the performance of the employees of the institution, the maintenance of the facilities could be improved. This study will act as reference material for academics in the FMM field. Also, the findings will pave the way for knowledge and measures to develop the workplace and help employees to improve their performance.

\section{Literature Review}

According to Dada et al. (2018), development of the FMM in higher education institutions is complex and cost intensive because it involves the provision of buildings, lecture halls, residences, staff offices, workshops, research laboratories, libraries, Health Resources Centres, and sport fields, to name a few. It also includes the provision of a stimulating learning environment with adequate safety considerations. Institution facility improvement and maintenance, as per Dada et al., are crucial aspects of institutional plant administration, which requires continuous consideration and cautious planning by managers.

Facility managers are primarily available to ensure the provision of programs and operations for all departments in universities by providing maintenance facilities and infrastructure which help the employees achieve the intended objectives. University infrastructure and maintenance are essential aspects of the university plant management; they 
require constant attention and careful planning by management to enhance employee performance (Fadahunsi et al., 2019).

Alsayyari et al. (2019) envisaged that facilities comprises of furniture, equipment, material supplies, working tools, and IT as well as grounds such as parking lots, gardens, sport fields, outdoor play areas, and outdoor learning areas. IHL need to handle the complexity and enable higher levels of employee performance; therefore, FMM is expected to play a key role (Lundgren et al., 2018) in achieving high levels of employee performance.

Several authors have classified many different models and types of maintenance, the most prominent of which were four dominant maintenance measurement models used by many companies and institutions: Total productive maintenance, condition-based maintenance, reliability-centred maintenance, and condition monitoring (Galen \& Gomez, 2018; Lundgren et al., 2018; Rossella et al., 2019). Although Fraser (2014) argued that condition monitoring is an integrated part of the other three all-inclusive models - namely, total productive maintenance, condition-based maintenance, and reliability-centred maintenance - these models have their own philosophy, application practices, and tools and techniques.

Fraser (2014) also described total production maintenance as productive maintenance that is performed by employees through various small group tasks on a wide basis in a company or institution. Total production maintenance depends solely on the machines, whereas condition-based maintenance, according to Galen and Gomez (2018), is based on detection and monitoring of that machines. Lundgren et al. (2018) noted that almost $98 \%$ of the equipment failures are preceded by warning signs and a certain abnormal error performance when a failure is about to occur. Reliability-centred maintenance, according to Fraser, is a procedure that is used to check the required maintenance of physical assets in their working context to evaluate and check what needs to be maintained to ensure the assets perform the functions they were intended for. Lundgren et al. noted that reliability-centred maintenance is more focused toward technology because it offers a reliable basis for assessing the required maintenance and guides the maintenance duties to the parts where attention is needed (i.e., what needs to be done).

Facility management has increased complex maintenance, therefore, institutions' facility managers are accountable to the top management concerning facility maintenance. Amaratunga et al. (2011) stated that in supporting the employees to perform the required duties, the top management of the institution requires information regarding the performance of the facilities. In addition, the contribution of facility managers should be assessed by the employees of the institution. Facility managers are under pressure to ensure the improvement of the performance of facilities of the institution to substantiate their accomplishments to the top management as well as to the employees.

Performance measures play an important role for facility managers - they provide information that guides the facility managers on how to improve facilities and direct the institution in achieving its goals and driving it toward new positive directions within the institution. Amaratunga et al. (2011) asserted strategies that facility managers can use to improve the performance of an institution by controlling resources, culture, and service delivery as well as change management in the supply chain.

To address teaching and learning during crises, Singh et al. (2021) conducted research to investigate the impact of combining the best of online and face-to-face learning in the post-COVID-19 pandemic. The researchers adopted an in-depth review of the evolution of this hybrid model of instruction, including the online approach catalyzed by the outbreak of COVID-19. Their findings preferred the "evidence-based approach" for instruction because it integrates the best of both traditional and online instructional methods.

Prior to the findings above, Dhawan, S., (2020), in his study of the "Online learning: A panacea in the time of COVID-19 crisis" advocates the growth of EdTech Start-ups during the time of pandemic and natural disasters. The researcher further suggestions that academic institutions should deal with challenges associated with online learning through alternating various platforms that can enhance performance.

Nik-Mat et al. (2011) specified that facility managers should emphasize not only decreasing the running cost of the facilities but also considering the effective and cost-efficient means of managing and maintaining assets of the institutions, which includes recognizing the effectiveness of the contributions of facility functions. Nik-Mat et al. further outlined that in some institutions, facilities managers are applauded and valued for their entrepreneurial skills and knowledge of the fundamentals of the institution. Their capabilities to obstruct and interpret the institutions' need for improvement in facilities strategies reinforces operational objectives to achieve institutional goals and gain a competitive advantage. Inclusively, this process shows the significant role performance measures play in the FMM of an institution in providing valuable information regarding the status of facilities of the institution. 


\section{Research Methodology}

This research study employed a quantitative research design whereby a survey questionnaire was used. The survey was made up of a predetermined set of questions distributed to the sample of respondents (Blanche et al., 2006). This process enabled the researcher to use statistical inference techniques on the collected data (Baruch \& Holtom, 2008). For this study, a sample was pulled up from the targeted population. The selection of a good sample is critical because it permits the generalization of the results to the general populace (Gall et al., 2007). The primary data were gathered from 150 participants using an adapted and modified structured questionnaire to solicit information related to FMM and employee performance. A simple random probabilistic sampling method was utilized to draw a sample of 150 respondents from the sample frame (list of employees), where the final data were analyzed using SPSS Version 24.0 for statistical inference.

\section{Results, Discussion, and Interpretation of Findings}

The data were organized and presented in frequency tables to make sense of the collected information and to achieve the objectives of the study. The analysis of the data involved examining the role of FMM and its effect on employee performance at an IHL. The samples were taken from 150 employees of the institution, where $58.0 \%$ of the respondents are women and $42.0 \%$ are men, and $37.3 \%$ of the respondents are in the age group of 35-44 years and $24.0 \%$ of the respondents are in the age group of $45-54$ years. Then, $20.7 \%$ of the respondents are in the age group of 55-64 years, followed by $16.0 \%$ of the respondents in the age group of 25-34 years. The remaining $2.0 \%$ of the respondents are under 24 years of age. Respondents were classified as academic staff (64.0\%) and support service $\operatorname{staff}(36.0 \%)$.

The respondents were asked about condition of their office elements such as plumbing, windows, roof, and doors (see Table 1).

Table 1. Office settings

\begin{tabular}{llll}
\hline Responses & Frequency & Percent & Cumulative percent \\
\hline Very poor & 7 & 4.7 & 4.7 \\
Poor & 29 & 19.3 & 24.0 \\
Fair & 82 & 54.7 & 78.7 \\
Good & 32 & 21.3 & 100.0 \\
Total & $\mathbf{1 5 0}$ & $\mathbf{1 0 0 . 0}$ & \\
\hline
\end{tabular}

\section{Source: Researcher}

Table 1 shows the majority (54.7\%) of the respondents expressed that the maintenance service performed by the facility department on office elementswere as follows: plumbing was good, windows were poor, roof was fair, and doors were very poor. Furthermore, $21.3 \%$ of the respondents believed that the maintenance service performed by the facility department based on office elements was good, and $19.3 \%$ of the respondents expressed that the maintenance service performed by the facility department based on office elements was poor. The remaining $4.7 \%$ of the respondents indicated that the maintenance service performed by the facility department based on office elementss was very poor. The results revealed that more than $70 \%$ of the respondents indicated that the institution had been doing a good job in the servicing of office elements s while the plumbing was good, windows were poor, roof was fair, and doors were very poor.

The respondents were asked about the effect of reliable internet network on employee performance (see Table 2).

Table 2. The effect of reliable internet on employee performance

\begin{tabular}{llll}
\hline Responses & Frequency & Percent & Cumulative Percent \\
\hline Negative effect & 5 & 3.3 & 3.3 \\
No effect & 12 & 8.0 & 11.3 \\
Positive effect & 35 & 23.3 & 34.7 \\
Very positive effect & 98 & 65.3 & 100.0 \\
Total & $\mathbf{1 5 0}$ & $\mathbf{1 0 0 . 0}$ & \\
\hline
\end{tabular}

Source: Researcher 
Based on the above table, the majority $(88.7 \%)$ of the respondents expressed that those services based on the reliability of an internet network had a constructive effect on their performance at work, whereas $65.3 \%$ of the respondents reported a very positive effect and $23.3 \%$ reported a positive effect. Only $8.0 \%$ of the respondents expressed that those services based on the reliability of the internet network had no effect on their performance at work. The remaining 3.3\% of the respondents believed that services based on the reliability of the internet network had a negative effect on their performance at work. The results revealed that the performance of more than $88 \%$ of the respondents was positively affected by the reliable internet network at the institution. Research has confirmed that new technological methods contribute to increased staff satisfaction and subsequent staff productivity. Current modern business technology is vital to businesses and institutions that need an internet connection to function and a fast network to be able to complete tasks effectively. According to Yeshambel et al. (2016), employers should provide relevant workforce equipment and a reliable internet connection to perform tasks and to improve productivity. Any unexpected internet outage can impose significant costs and losses on any business that relies on internet access to get work done.

The respondents were asked about the effect of cleaning and sanitation of their workstations on employee performance (see Table 3).

Table 3. Effect of cleaning and sanitation of workstations on employee performance

\begin{tabular}{llll}
\hline Responses & Frequency & Percent & Cumulative percent \\
\hline Very negative effect & 12 & 8.0 & 8.0 \\
Negative effect & 64 & 42.7 & 50.7 \\
No effect & 4 & 2.7 & 53.3 \\
Positive effect & 44 & 29.3 & 82.7 \\
Very positive effect & 26 & 17.3 & 100.0 \\
Total & $\mathbf{1 5 0}$ & $\mathbf{1 0 0 . 0}$ & \\
\hline
\end{tabular}

Source: Researcher

Table 3 shows that the majority $(50.7 \%)$ of the respondents expressed that the maintenance services based on cleaning and sanitation of their workstation had an undesirable effect on their performance, whereas $8 \%$ of the respondents reported a very negative effect, and $42.7 \%$ reported a negative effect. Moreover, $46.7 \%$ of the respondents expressed that the maintenance services based on cleaning and sanitation of workstations had a constructive effect on their performance, $17.3 \%$ reported a very positive effect, and $29.3 \%$ reported a positive effect. The remaining $2.7 \%$ of the respondents expressed that the maintenance services based on cleaning and sanitation of workstations had a negative effect on their performance. The results revealed that more than $50 \%$ of the respondents believed their performance had been affected by services based on the cleaning and sanitation of their workstations. Smith (2018) elucidated that a typical office keyboard can hold over 7,500 bacteria at any one time, and viruses such as flu can stay on office desks or computers for 24 hours or more. He further stated that such an environment can have a negative effect on workplace productivity, with employees finding it difficult to encourage themselves to work at their best when confronted with a dirty office every morning.

The respondents were asked about the quality of lecture halls and laboratories (see Table 4).

Table 4. Quality of lecture halls and laboratories

\begin{tabular}{llll}
\hline Responses & Frequency & Percent & Cumulative percent \\
\hline Very poor & 141 & 94.0 & 94.0 \\
Poor & 9 & 6.0 & 100.0 \\
Total & $\mathbf{1 5 0}$ & $\mathbf{1 0 0 . 0}$ & \\
\hline
\end{tabular}

Source: Researcher

Table 4 shows that the majority $(94.0 \%)$ of the respondents expressed that the quality of the lecture halls and laboratories at the institution was very poor, and $6.0 \%$ of the respondents indicated that the quality of lecture halls and laboratories at the institution was poor. The results confirm that the institution does not have quality lecture halls and laboratories. 
The respondents were asked about the functionality of equipment provided for teaching and learning, such as projectors and audio enhancers, in lecture halls (see Table 5).

Table 5. Functionality of equipment

\begin{tabular}{llll}
\hline Responses & Frequency & Percent & Cumulative percent \\
\hline Service not available & 150 & 100.0 & 100.0 \\
\hline
\end{tabular}

Source: Researcher

Based on the above table, $100 \%$ of the respondents indicated that the institution does not provide functional equipment for teaching and learning, such as projectors and audio enhancers.

The respondents were asked about adequate communication between maintenance department and users (see Table 6).

Table 6. Communication between maintenance department and users

\begin{tabular}{llll}
\hline Responses & Frequency & Percent & Cumulative percent \\
\hline Never & 31 & 20.7 & 20.7 \\
Rarely & 89 & 59.3 & 80.0 \\
Sometimes & 28 & 18.7 & 98.7 \\
Often & 2 & 1.3 & 100.0 \\
Total & $\mathbf{1 5 0}$ & $\mathbf{1 0 0 . 0}$ & \\
\hline
\end{tabular}

Source: Researcher

Table 6 shows that the majority $(59.3 \%)$ of the respondents expressed that there is rarely communication between the facility department and end users; $20.7 \%$ of the respondents indicated that the facility maintenance department never communicates with the end users of the facilities. A further $18 \%$ of the respondents expressed that sometimes the facility department does communicate with the end users, and the remaining $1.3 \%$ of the respondents stated that there is often communication between the facility department and end users of the facilities at the institution. The results confirm that there is a lack of communication between the facility maintenance department and the end users of the facilities. Katcher (2020), in his study, elucidated that two out of three employees confirmed that the communication between inter-departments in their organization was quite poor. He indicated that poor communication leads to a decrease in the quality of the products and services offered by the company. Additionally, Christiansen (2020) stated that communication between departments is one of the key aspects of an organization that helps to keep it running efficiently and productively.

\section{Conclusions and Recommendations}

Objective 1 of the study was to examine the impact of FMM on the performance of the employees at an IHL. The research findings have confirmed that FMM plays a substantial role on the performance of the employees at the institution, and the impact has a negative effect on their performance.

Objective 2 of the study was to evaluate whether the current facilities procured by the institution create a suitable, conducive, and adequate working environment. The findings confirmed that the current facilities at the institution are not suitable, adequate, or conducive for workers to perform their duties efficiently.

The study emphasized the importance of FMM and its role in how the employees perform in the workplace. The study also found that FMM at the institution has a negative effect on the performance of employees. The success of any higher education institution depends on the facilities it has. Therefore, it is paramount that the management should consider appropriate management of these facilities for the success of the institution. The study will assist the management to comprehend the critical issues affecting the performance of the employees.

In institution of higher learning, a conducive environment starts at the offices of employees, further to the lecture halls, laboratories and moreover, the entire campus. Departments have different needs that should be addressed by facility managers; therefore, facility managers need to ensure a periodic performance assessment program for all of the facility's equipment. Facility managers or supervisors should always follow up on maintenance services carried out by means of inspecting when tasks are completed for a high-quality standard of service, and if there is a problem, it would be easily seen and fixed quickly without occurring additional costs. 
To also ensure that the policies and procedures are followed accordingly, facility managers should initiate task briefings before each task is performed to ensure the facility employees have a clear understanding of the activity to be completed. An efficient method for preparation, scheduling, and coordinating facility maintenance tasks needs to be applied to ensure effective maintenance service is achieved on time, workers are kept safe, and facility maintenance competence is improved.

University facilities are vital assets of the university; therefore, it is important for management and all stakeholders to prioritize FMM so that these facilities can provide support to the fundamental mission, vision, and objectives of the university in research, teaching, and learning. The matter of safety is of major importance to the employees, and the provision of fire safety equipment is required by law. Thus, the institutional management needs to ensure that they comply with the South African Occupational Health and Safety Act 85 of 1993, which stipulates the standard legal regulations to protect workers from any hazards, threats, incidents, or mortalities.

Finally, the institution should adopt a strategy to maintain their buildings and equipment, also provide all the necessary equipment, such as fire extinguishers, pump systems, fire alarms, and sprinkler systems, for not only the safety of workers but also to protect the property and assets of the institution.

\section{References}

Alsayyari, A., Alblawi, A., Nawab, M., \& Alosaimi, A. (2019). A conceptual framework for facility management in higher education institutions in Saudi Arabia. Tem journal, 22 February, 8(1), 157-164. DOI: 10.18421/TEM81-22,

Amaratunga, D., Kulatunga, U., \& Baldry, D. (2011). Performance measurement applications in facilities management: an investigation into the future directions. Research institute for the built and human environment, $1-16$.

Baruch, Y., \& Holtom, B. C. (2008). Survey response rate levels and trends in organisational research. Human relations, 61(8), 1139-1160.https://doi.org/10.1177/0018726708094863

Blanche, M. T., Blanche, M. J. T., Durrheim, K., \& Painter, D. (2 ${ }^{\text {nd }}$ Edition. 2006). Research in practice: Applied methods for the social sciences, UCT Press, Cape Town.

Christiansen, B. (2020). BeeKeeper. [Online] Available at: https://www.beekeeper.io/blog/why-good-communication-betweenmanufacturing-departments-matters/ [Accessed 09 July 2020].

Dada, M. R., Oladapo, S. O., \& Olayiwaola, M. M. (2018). Influence of educational facilities maintenance practices on quality assurance in public higher institution in Lagos state, Nigeria. Global institute for Research \& Education, March-April, 7(2), 51-54. https://doi.org/10.24105/gjcmp.7.2.1809

Dhawan, S. (2020). Online learning: A panacea in the time of COVID-19 crisis. Journal of Educational Technology Systems, 49(1), 5-22. https://doi.org/10.1177/0047239520934018

Fadahunsi, J. O., Utom, A. J., Ayedun, C., \& Oloke, O. C. (2019). Benefits of the adoption of Facilities Management practices in tertiary institutions: A case study of Covenant University. IOP Conf. Series: Materials Science and Engineering. https://doi.org/10.1088/1757-899X/640/1/012032

Fraser, K. (2014). Facility Management: the strategic selection of maintenance system. Journal of Facilities Management, 12(1), 1-21. https://doi.org/10.1108/JFM-02-2013-0010

Galen, M. H., \& Gomez, E. A. M. (2018). A review of maintenance management models: Application for the clinic and hospital environment. The International Journal of Engineering and Science, 9(1-17), 7.

Gall, G. Gall, J. P., \& Borg, R. (2007). Educational Research, $8^{\text {th }}$ Edition. Boston: Pearson Edu.

Lundgren, C., Skoogh, A., \& Bokrantz, J. (2018). Quantifying the effects of maintenance: A literature review of maintenance models. Elsevier, 1305-1310. https://doi.org/10.4236/aces.2012.24063

Nik-Mat, N. E. M., Kamaruzzaman, S. N., \& Pitt, M. (2011). Assessing the maintenance aspect of facilities management through a performance measurement system: A Malaysian case study. Elsevier, 329-338. https://doi.org/10.1016/j.proeng.2011.11.174

Occupational Health and Safety Act. (Act 85 of 1993). Pretoria: Government print. 
Ofide, B., Jimoh, R., \& Achuenu, E. (2015). Assessment of building maintenance management practices of higher education institution in Niger state, Nigeria. Research Gate, 15(2), 1-14. https://doi.org/10.22452/jdbe.vol15no2.4

Ogbeifun, E. (2016). Evaluating and aligning facilities management operations in a South African higher education institution: A case study. University of Johannesburg, Thesis- PHD.

Oladokun, S. O., \& Ajayi, C. A. (2018). Assessing user's perception of facility management services in a public university; A case study approach. Journal of Facility Management and Research, 2(2), 62-73. https://doi.org/10.22361/jfmer/00071

Rossella, M., Maurizio, N., Francesco, P., \& Andrej, T. (2019). A methodology for a performance information model to support Facility Management. MDPI, 11, 1-25. https://doi.org/10.3390/su11247007

Singh, J., Steele, K., \& Singh, L. (2021). Combining the Best of Online and Face-to-Face Learning: Hybrid and Blended Learning Approach for COVID-19, Post Vaccine, \& Post-Pandemic World. Journal of Educational Technology Systems, p.00472395211047865. https://doi.org/10.1177/00472395211047865

Smith, D. (2018). Can a clean office boost productivity? [Online] Available at: https://facilityexecutive.com/2018/05/can-clean-office-boost-productivity/ [Accessed 21 June 2020].

Waller, Lemoine, Mense, Garretson \& Richardson (2019). Global Higher Education in a VUCA World: Concerns and projections. Journal of Education and Development, 3(2). https://doi.org/10.20849/jed.v3i2.613

Yeshambel, T., Belete, M., \& Mulualem, Y. (2016). Impact of online social networking on employee's productivity at workplace in University of Gondar: A case study. International Journal of Computer Applications, 135(3). https://doi.org/10.5120/ijca2016907844

\section{Copyrights}

Copyright for this article is retained by the author(s), with first publication rights granted to the journal.

This is an open-access article distributed under the terms and conditions of the Creative Commons Attribution license (http://creativecommons.org/licenses/by/4.0/). 